\title{
Design and construction of a prototype for acidity level control in coal mining liquid effluents
}

\author{
JM Salamanca Universidad Pedagógica y Tecnológica de Colombia, Colombia \\ HE Rodríguez Universidad Pedagógica y Tecnológica de Colombia, Colombia \\ MM Moreno Universidad Pedagógica y Tecnológica de Colombia, Colombia
}

\begin{abstract}
It is a challenge of modern industry to develop processes that do not pollute the environment, most importantly water. The mining industry is no exception, and in turn must minimise environmental impact on water sources in or around areas of exploitation (Garner et al. 2012). The management of drainage in the depth of the mine is a problem due to high costs, and it is important to understand that the cost of the consumption of electric energy rises according to the size of the mine and the quantity of drainage.

This paper describes the design and implementation of a prototype to neutralise the acid water of mining in the didactic coal mine located in Morcá (Sogamoso, Colombia), which belongs to the Centro Nacional Minero (National Mining Centre), Servicio Nacional de Aprendizaje (SENA, Sogamoso, Colombia). The neutralisation of these acidic waters aims to minimise the environmental impact produced by these liquids, when they are discharged into nearby water sources. The neutralisation method is 'additives base', which comprises mixing a basic agent; in this case, caustic soda ( $\mathrm{NaOH}$ ) at a concentration of $1 \mathrm{Normal}(1 \mathrm{~N})$ was used. In order to carry out this process, the system model is estimated and proportional plus integral (PI), algebraic, fuzzy logic and sliding mode controllers were applied to the prototype. A comparison of the performances of the different controllers showing the response time overshoot, steady state error and magnitude of the control signals are shown and analysed.
\end{abstract}

Keywords: $p H$, acid water, caustic soda

\section{Introduction}

The use of water in coal mining plays a very important role. This is because large amounts are used in the separation of the ore from its surroundings. Regardless of whether it is in underground or surface media, even in mineral processing water is used to separate the useful mineral from other useless minerals (Kemmer et al. 1989). The water used in the mining process is extracted from the mines, and in some cases it has to be pumped over considerable distances, from the bottom of the mine to the surface. When the ore extracted is coal or other minerals, a reaction occurs between the forms of iron pyrites with water and at that moment acid waters are generated (Russell et al. 2012). There is a very serious problem in the mining of coal when the acid waters generated in this operation are drained to healthy water sources without adequate treatment (Barettino \& Pérez 2005). According to Kemmer et al. (1989), when acid waters are incorrectly disposed of, they alter the oxygen levels of the rivers or lagoons close to the area where mineral exploitation takes place. At the moment the basic composition of the water is altered, certain abnormal events in the biology and the ecology of the environment occur. This leads to a decrease in biota in the ecosystem. In some cases, the colour of the affected water is black and it can even take on a foul odour (Barettino \& Pérez 2005). The hydrogen potential $(\mathrm{pH})$ serves as a basis for the measurement of acidity levels present in liquid mining effluents. The $\mathrm{pH}$ is an indicator of the acidity of a substance and is determined by the number of free hydrogen ions $\left(\mathrm{H}^{+}\right)$. The $\mathrm{pH}$ of the water may vary between zero and 14 . When the $\mathrm{pH}$ of a substance is greater than seven, it is a basic substance, and if it is below seven, it is an acidic substance. 
Taking into account the water studies carried out by the National Mining Centre, SENA (Monguí-Galvis et al. 2015), the iron content of the mining effluents is $123 \mathrm{ppm}$ with a permissible value of $0.3 \mathrm{ppm}$ as established by Betancourt \& Ramírez (2007). The colour of water before and after treatment is orange and the $\mathrm{pH}$ level of the water is 3.5. According to the resolution previously mentioned, the $\mathrm{pH}$ level must be between 6.5 and 9. The ideal pH value of water is seven. One method for neutralising the acidity present in the water is that of the base additives, which consists of the addition of compounds such as sodium hydroxide, limestone, lime or sodium carbonate, which neutralises the acid. In this case caustic soda $(\mathrm{NaOH})$ is used with a concentration of 1 Normal $(1 \mathrm{~N})$.

The titration curve between an acid and a base $(\mathrm{NaOH})$ is shown in Figure 1.

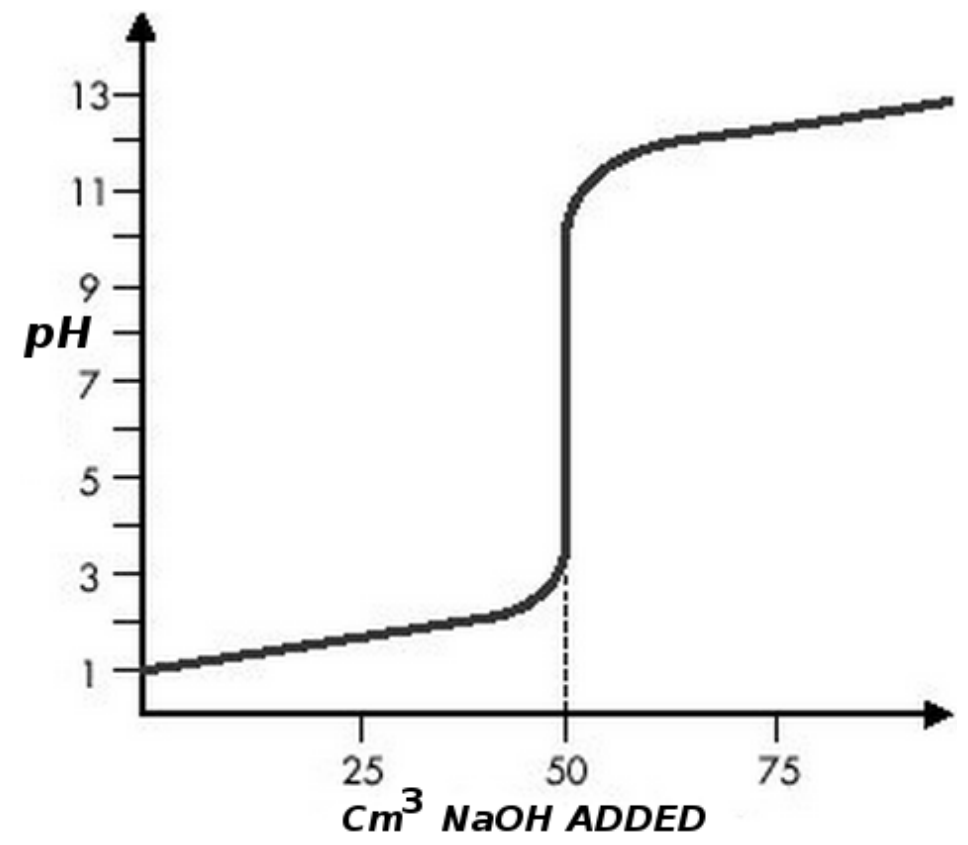

Figure 1 Base acid titration curve

In this paper, a prototype is considered which has four tanks to perform the neutralisation of the waters. For this system, traditional controller with proportional plus integral plus derivative action (PID) and modern control strategies such as fuzzy logic, algebraic and sliding modes are implemented and tested as a solution to control the acidity levels of the acidity liquid mining effluents. The performance of these control strategies is evaluated considering aspects such as:

- Response time.

- Setting time.

- Steady state error with respect to the reference.

The paper is organised as follows: in Section 1, an introduction explaining generalities about the generation of acid waters as well as the solution and objectives of the control system is given. In Section 2, the prototype design and implementation procedure for the neutralisation of acid waters is presented. In Section 3 , the modelling of the plant is presented in order to obtain a model serving to design the controllers. In Section 4, the design of the different control strategies that are applied to the prototype is presented. In Section 5, the analysis of the results of the implemented control strategies and their performance according to the evaluation parameters is outlined. Finally, in Section 6, the conclusions are presented. 


\section{Design and implementation of the prototype for analysis and control of the acidity level in liquid mineral effluents}

The design and elaboration of the prototype structure was considered by taking into account the objective of neutralising the acidity present in the mine effluents of the didactic mine from the National Mining Centre, SENA.

The prototype consists of four tanks:

- The first tank stores the acid waters to be treated.

- The second tank is used to contain the neutralising agent; in this case caustic soda $(\mathrm{NaOH})$ is used.

- The third tank fulfils the function of the reactor tank where the neutralisation takes place.

- The fourth tank stores the neutralised effluents.

Figure 2 shows the implemented prototype diagram, and Figure 3 shows the real prototype.

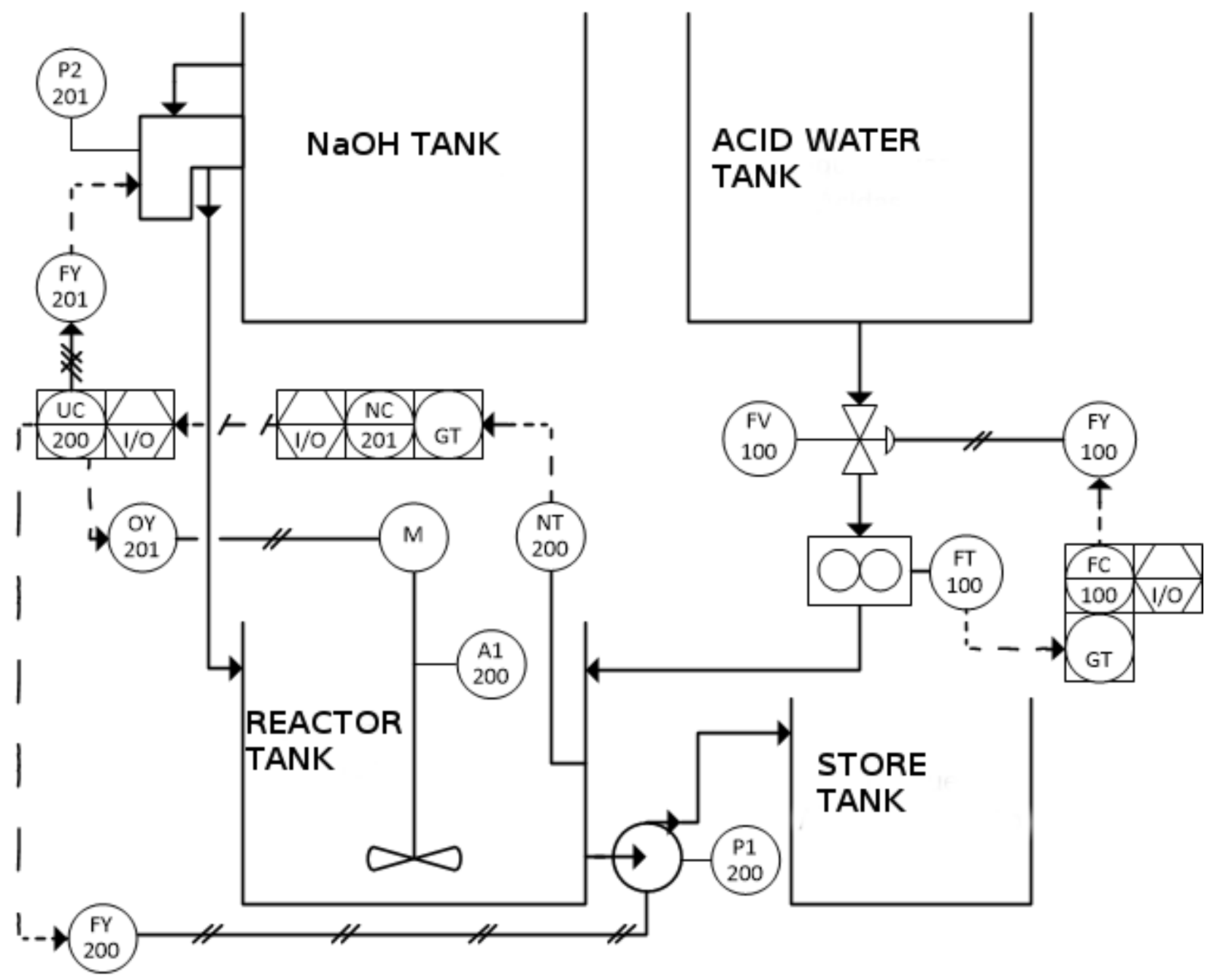

Figure 2 Implemented prototype diagram

The $\mathrm{pH}$ sensor in the reactor tank is located far from the mixer and the source of $\mathrm{NaOH}$ to prevent them from producing abrupt variations in sensor measurements and inhibiting control strategies. 


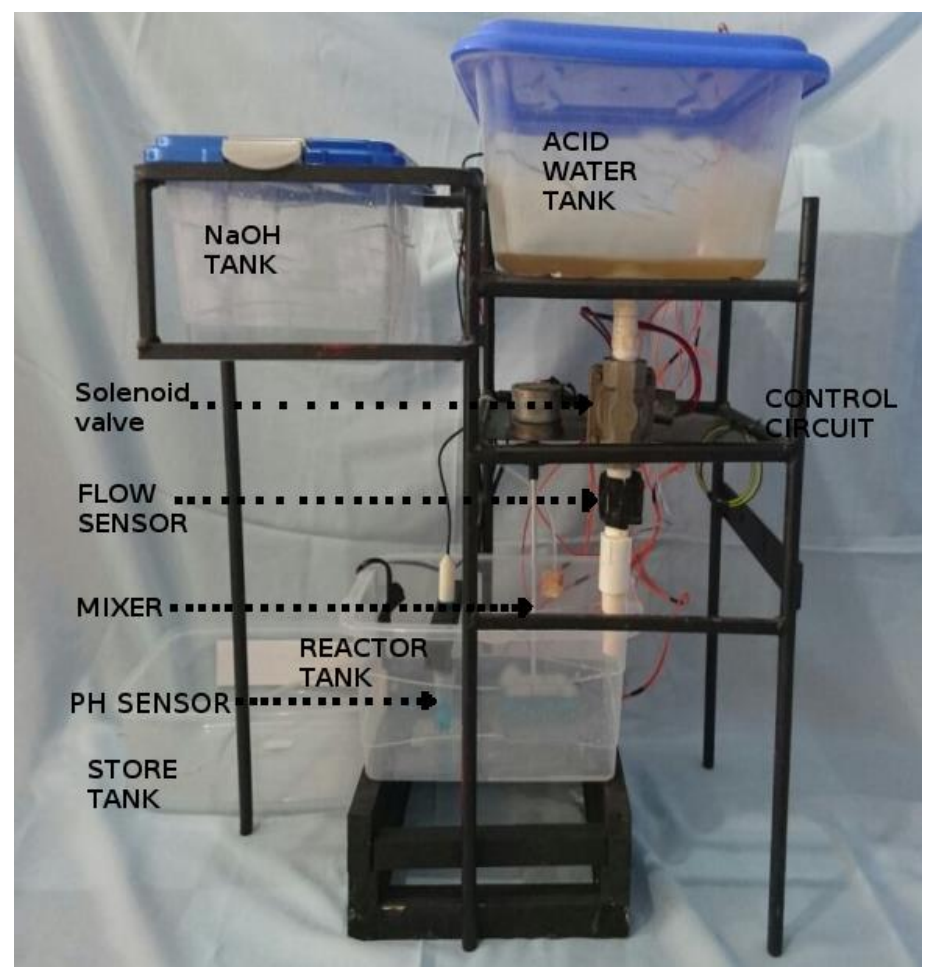

\section{Figure 3 Real prototype implemented}

\section{System modelling}

In order to obtain the model of the system, a substance that flows through a pipe with a known delay is considered. Its purpose is to reach the reactor tank with a perfect mixture (Bequette 1998; Smith \& Corripio 2006). Accordingly, Equations 1 and 2 describe the process:

$$
\begin{gathered}
V_{m}(t) \dot{C}_{0}(t)=q(t)\left[C_{\text {in }}(t-\theta)-C_{0}(t)\right] \\
\theta(t)=\frac{V_{d}}{q(t)}
\end{gathered}
$$

where:

$$
\begin{aligned}
& C_{o}(t)=\text { concentration in the outflow tank. } \\
& C_{\text {in }}(t)=\text { concentration in the inlet mixing tank. } \\
& V_{m}(t)=\text { volume of the substance in the tank in litres }(L) . \\
& q(t)=\text { inlet flow to the tank }(L / s) . \\
& V_{d}=\text { volume in the pipe }\left(\mathrm{m}^{3}\right) . \\
& \theta(t)=\text { delay of the substance }(\mathrm{NaOH}) \text { to reach the reactor tank. }
\end{aligned}
$$

Assuming $V_{m}(t)=V_{m 0}$.

The equation of the system is expressed by Equation 3

$$
\dot{C}_{0}=\frac{q_{0}}{V_{m o}} C_{0}(t)+\frac{q_{0}}{V_{m 0}} C_{i n}(t-\theta)
$$

where:

$\theta=V_{d} / q$ y $q(t)=q_{0}$ (constant) and applying the Laplace transform we obtain the transfer function of the process given by Equation 4 .

$$
\frac{C_{0}(S)}{C_{i n}(S)}=\frac{K_{p} e^{-\theta S}}{\tau_{o} S+1} ; K_{p}=1 ; \tau_{0}=V_{m 0} / q_{0}
$$


Considering the parameters determined in the prototype construction, it is assumed that $V_{m}(t)$ has a value of $1(\mathrm{~L}), q(t)$ with a measure of $6(\mathrm{ml} / \mathrm{s})$ and $\theta(\mathrm{t})$ with a delay of $10(\mathrm{~s})$. With the aforementioned values, the model of the plant is represented by Equation 5 .

$$
G_{p}(s)=\frac{1 e^{-10 s}}{166.67 s+1}
$$

In order to carry out the validation of the design model, the Ziegler and Nichols method or open-loop response curve is used as shown in Figure 4. This method (Kiam Heong et al. 2005) consists of applying a step to the control signal, and the changes in the measured or controlled variable are recorded. By applying this method, the characteristics of the system to be controlled are obtained.

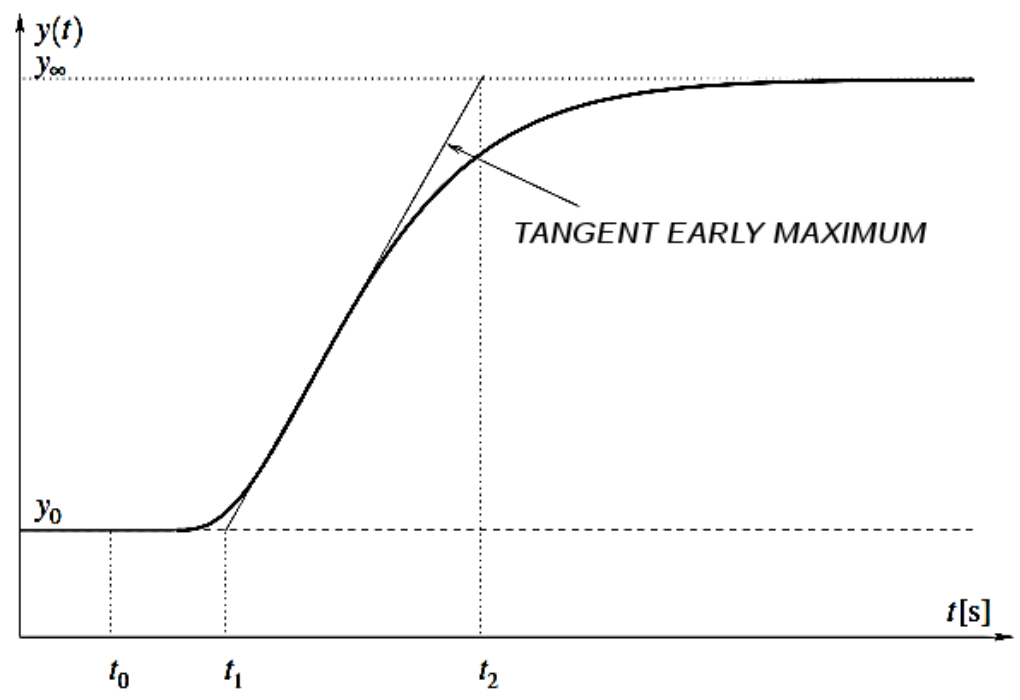

Figure 4 Open-loop response

From the response curve, Equation 6 is obtained:

$$
K_{0}=\frac{y_{\infty}-y_{0}}{u_{\infty}-u_{0}} ; \tau_{0}=t_{1}-t_{0} ; \gamma_{0}=t_{2}-t_{1}
$$

With these parameters, the transfer function (Equation 7) of the system is:

$$
G_{\mathrm{p}}(s)=\frac{K_{0} e^{-\tau_{0} s}}{\gamma_{0} s+1}
$$

In order to obtain the system model a step is applied to the control signal of the peristaltic pump. Thus, the $\mathrm{pH}$ variation in the water to be treated with respect to the sodium hydroxide dosage $(\mathrm{NaOH})$ in the reactor tank is derived. Figure 5 shows the response curve obtained.

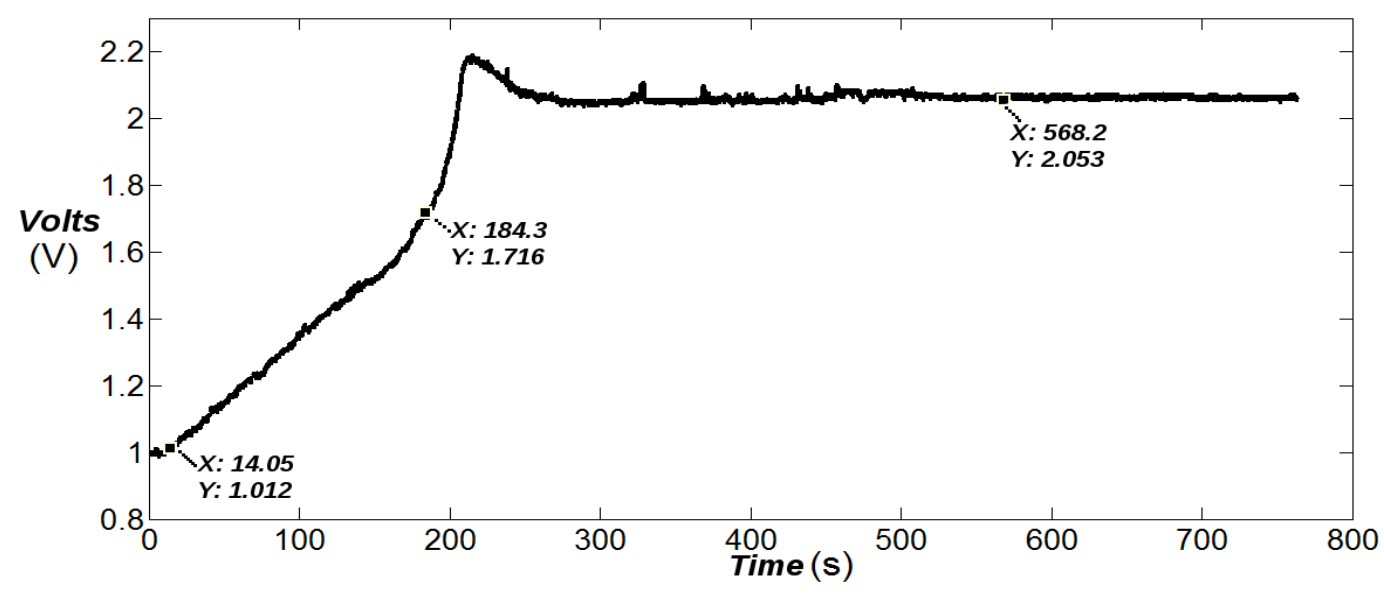

Figure 5 System response curve 
From the response curve given in Figure 5, an overshoot before the signal stabilises can be observed. This response is similar to a second order system, but this overshoot is given by the measurements in the $\mathrm{pH}$ sensor while stabilising the concentration in the reactor tank. It is known that the prototype corresponds to a system of first order with dead time. From this view point, to obtain the transfer function, the required data was acquired from the response curve (Figure 5) and, for their validation, were compared with the results obtained by Kang et al. (2009) and Rivero Ochoa and Chávez Cuadros (2010).

Equation 8 is used to find the parameters where $K_{p}=1.051 ; \tau_{0}=14.05$ and $\mathrm{y} \gamma_{0}=170.25$. With the parameters found, the system transfer function was of the form in Equation 7.

$$
\mathrm{G}_{\mathrm{p}}(\mathrm{s})=\frac{1.051 e^{-14.065 s}}{170.25 \mathrm{~s}+1}
$$

When comparing Equation 5, which represents the equation of the ideal model, with Equation 8, representing the experimental model, it can be seen that the parameters do not differ much; therefore, we chose Equation 8 for the design of the controllers. For more information about the behaviour of this model, see Distefano III et al. (1992).

\section{$4 \quad$ Control strategies applied to the system}

Taking the model of the plant, the next step is to study the implementation of the controllers. The implementation of the drivers utilised MATLAB Simulink (The MathWorks, Inc. 2017) together with the Arduino UNO and MEGA 2560 cards. For more information see Banzi (2011), Goilav and Loi (2016) and Pedrera (2017).

As mentioned in the introduction, the implemented drivers were:

- PID controller.

- Algebraic method controller.

- Fuzzy logic-based controller.

- Sliding mode controller.

\subsection{Proportional plus integral controller}

The general expression of the proportional plus integral (PI) control signal (Åström \& Hägglund 2006; Kiam Heong et al. 2005) is given by Equation 9.

$$
u(t)=K_{p}\left[e(t)+\frac{1}{T_{i}} \int_{-\infty}^{t} e(\tau) d \tau\right]
$$

From the process model, the controller parameters are calculated using the integral minimum error criteria; the integral of the error square (ICE) (Åström \& Hägglund 2006) represented by $\int_{0}^{\infty} e(t)^{2} d t$ and the integral of the absolute value of the time-weighted error (ITAE) (Åström \& Wittenmark 2011) determined by $\int_{0}^{\alpha} t|e(t)| d t$. Table 1 shows the equations for finding the parameters of the controllers $\mathrm{P}$ and $\mathrm{PI}$ depending on the implemented criterion. On the other hand, a PID controller by location of poles in a closed loop without using the previous criteria was also designed. The obtained parameters, in this case, were $K_{P}=\frac{0.9 \gamma_{0}}{K_{0} \tau_{0}}$ and $T_{i}=3 \tau_{0}$.

From the system model given by Equation 4, a PI controller is chosen due to the system time constant. The parameters of the PI controller with the criterion (ICE) are $K_{p}=13.5831 ; T_{i}=54.7623$, and with the criterion (ITAE) the parameters are $K_{p}=9.3515$ and $T_{i}=46.3135$. For the location of poles in a closed loop without using the previous criteria, the parameters of the controller are $K_{p}=10.3765$ and $T_{i}=42.15$. 
Table 1 Criteria of minimum integral of the error

\begin{tabular}{llllllll}
\hline \multirow{2}{*}{ Controller } & \multicolumn{1}{c}{ P } & \multicolumn{5}{c}{ PI } \\
& $\boldsymbol{K}_{\boldsymbol{P}}=\frac{\boldsymbol{a}}{\boldsymbol{K}}\left(\frac{\boldsymbol{t}_{\mathbf{0}}}{\boldsymbol{t}}\right)^{\boldsymbol{b}}$ & \multicolumn{4}{c}{$\boldsymbol{K}_{\boldsymbol{P}}=\frac{\boldsymbol{a}_{\mathbf{1}}}{\boldsymbol{K}}\left(\frac{\boldsymbol{t}_{\mathbf{0}}}{\boldsymbol{t}}\right)^{\boldsymbol{b}_{\mathbf{2}}}$} & $\boldsymbol{\tau}_{\boldsymbol{i}}=\frac{\boldsymbol{t}}{\boldsymbol{a}_{\mathbf{2}}}\left(\frac{\boldsymbol{t}_{\mathbf{0}}}{\boldsymbol{t}}\right)^{\boldsymbol{b}_{\mathbf{2}}}$ \\
\hline Criteria & $\mathrm{a}$ & $\mathrm{b}$ & $\mathrm{a}_{1}$ & $\mathrm{~b}_{1}$ & $\mathrm{a}_{2}$ & $\mathrm{~b}_{2}$ \\
ICE & 1.411 & -0.917 & 1.305 & -0.959 & 0.492 & 0.739 \\
IAE & 0.902 & -0.985 & 0.984 & -0.986 & 0.608 & 0.707 \\
ITAE & 0.490 & $-1,084$ & 0.859 & -0.977 & 0.674 & 0.680 \\
\hline
\end{tabular}

\subsection{Algebraic controller}

For the design of the controller by algebraic methods, the continuous time model (Equation 4) is discretised assuming the input generated by a zero order hold. A discrete time reference model is generated in accordance with the proposed objectives and the comparison between the discretised model of the plant and the reference model yields the equations of the controller. The controller is then implemented in MATLAB Simulink (The MathWorks, Inc. 2017), with which it is intended that the system will behave as the desired reference model (Figure 6). In the reference model, desired specifications such as response time, peak, and steady state error are incorporated for the closed-loop system. For more details see Salamanca (2009).

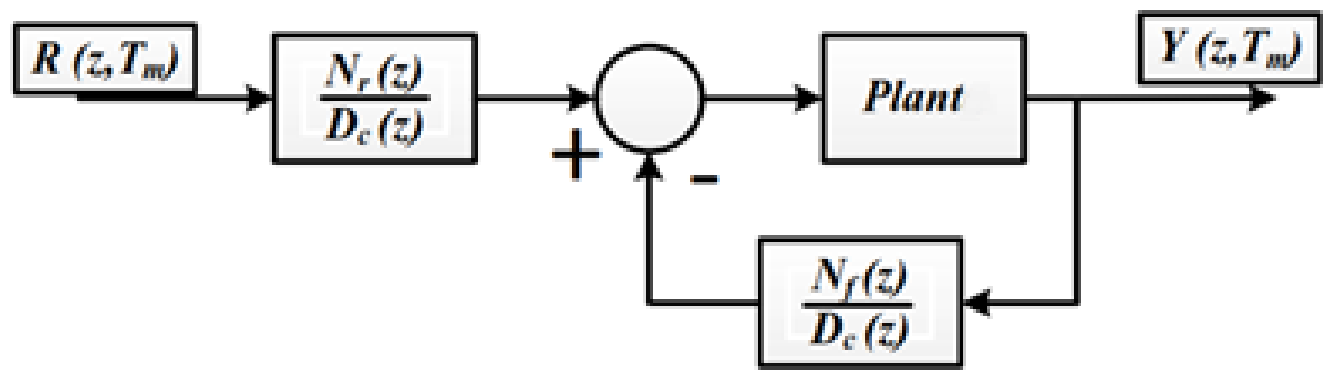

Figure 6 Schematic of discrete algebraic controller

The plant model used was obtained by discretisation with input generated by a zero order hold with a sample time of two seconds of the model given by Equation 8 .

The discrete transfer function $\frac{N r(z)}{D c(z)}$, which is a component of this controller, is defined by Equation 10.

$$
\frac{\operatorname{Nr}(\mathrm{z})}{\operatorname{Dc}(\mathrm{z})}=\frac{81.47 \mathrm{z}^{7}}{\mathrm{z}^{7}+0.9883 \mathrm{z}^{6}+0.9768 \mathrm{z}^{5}+0.9654 \mathrm{z}^{4}+0.9541 \mathrm{z}^{3}+0.943 \mathrm{z}^{2}+0.9319 \mathrm{z}+0.9211}
$$

The discrete transfer function $\frac{N f(z)}{D c(z)}$, the other component of the controller, is defined in Equation 11.

$$
\frac{N f(z)}{D c(z)}=\frac{74.16 z^{7}}{z^{7}+0.9883 z^{6}+0.9768 z^{5}+0.9654 z^{4}+0.9541 z^{3}+0.943 z^{2}+0.9319 z+0.9211}
$$

\subsection{Fuzzy logic controller}

Fuzzy logic control provides a formal methodology for representing, manipulating and implementing a human's heuristic knowledge about how to control a system (Passino \& Yurkovich 1998). A fuzzy logic controller with its basic components is shown in Figure 7. The fuzzy logic controller can be considered an artificial decision-maker that operates in a closed-loop system in real time. 


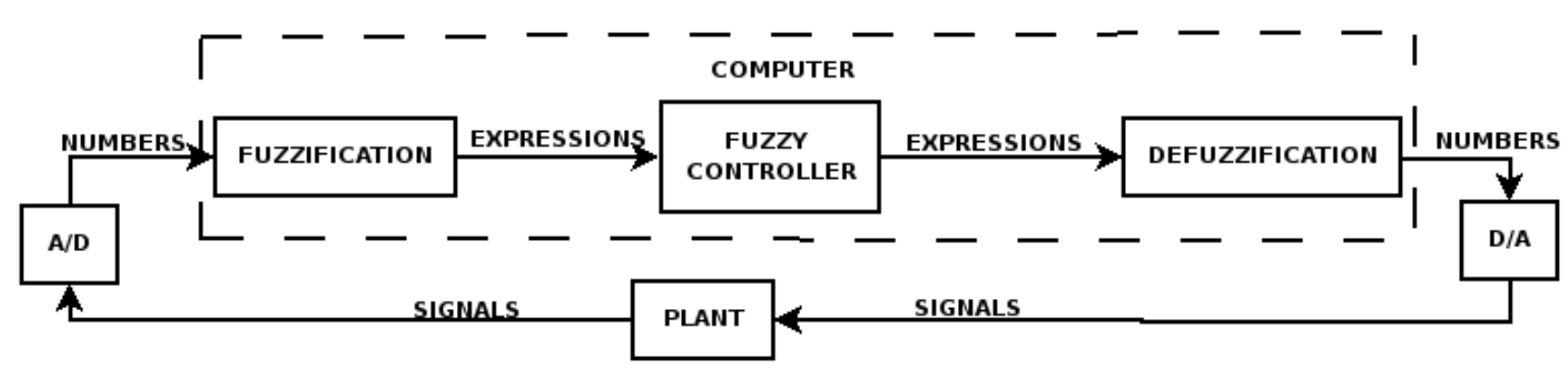

Figure 7 Controller schemes using fuzzy logic

The fuzzy logic controller is composed of the following elements (Figure 7):

- A rule base (a set of the rules), which contains a fuzzy logic quantification of the expert's linguistic description of how to achieve good control.

- An inference mechanism (also called an 'inference engine' or 'fuzzy inference' module), which emulates the expert's decision-making in interpreting and applying knowledge about how best to control the plant.

- A fuzzification interface, which converts controller inputs into information that the inference mechanism can easily use to activate and apply rules.

- A defuzzification interface, which converts the conclusions of the inference mechanism into actual inputs for the process.

The variables in a fuzzy controller (Figure 8) are represented by the degree of membership to fuzzy sets that represent the possible values that the variables can take in the actual process. The fuzzy sets, in this process, are represented by trapezoidal and triangular-type membership functions. The operations between the subsets of the controller are given by Bojadziev and Bojadziev (1996); and Passino and Yurkovich (1998). The logical conjunction 'AND', where the controller rules, considers the following notation: High: High, Med: Medium, Low: Low, Zero: Zero, TClosed: Completely closed, 1Q: 25\%, 2Q: 50\% of the pump and TOpen: Totally open.

The fuzzy set for the system entry is called 'Error'; it contains four subsets called 'High', 'Med', 'Low', and 'Zero'. The universe of this set is comprised between -9 and 9 since they are the maximum errors that exist in the $\mathrm{pH}$ measurements of the prototype. In this case, we used trapezoidal and triangular functions as shown in Figure 8. At the output of the controller, a discourse universe between 0.5 is selected. For the output, a fuzzy set called 'Peristaltic' is chosen. This choice was made because this variable will be entered into the peristaltic pump. The 'Peristaltic' set is divided into four subsets named 'TClosed', ' $1 Q^{\prime}$ ', '2Q' and 'TOpen'. Triangular functions are used as shown in Figure 9.

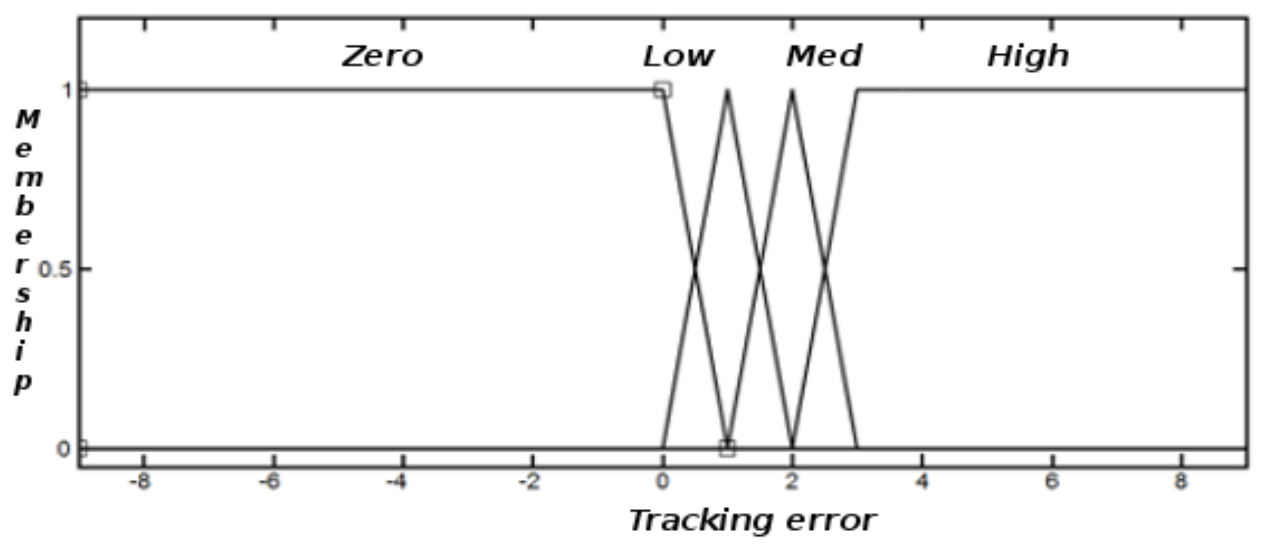

Figure 8 Subsets belonging to the error set 


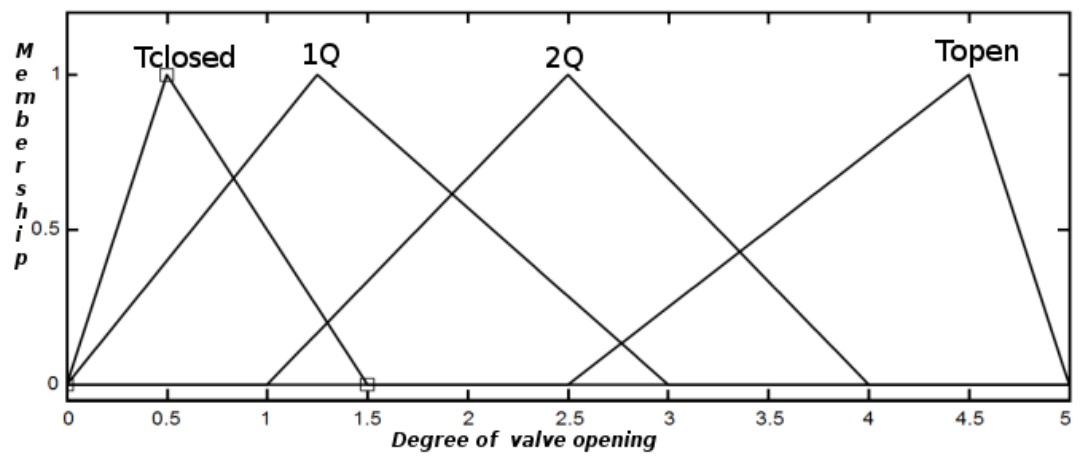

Figure 9 Subsets belonging to the peristaltic assembly

To establish the operations between the input and output subsets, the AND logic connector is used as follows:

- If (error is zero) then (Peristaltic is TClosed).

- If (error is low) then (Peristaltic is 1Q).

- If (error is half) then (Peristaltic is $2 Q$ ).

- If (error is high) then (Peristaltic is TOpen).

Figure 10 shows the control signal applied by the controller to the peristaltic pump as a function of the $\mathrm{pH}$ concentration error.

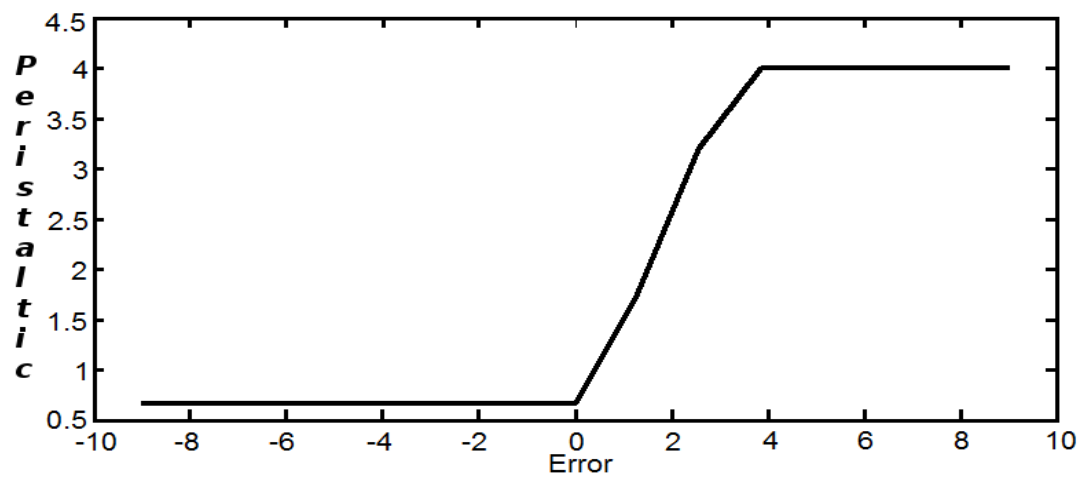

Figure 10 Fuzzy logic controller graphs (peristaltic versus error)

\subsection{Controller by sliding modes}

For the design of this type of controllers (Evangelista 2012; Salamanca et al. 2010) Equation 12 is taken into account.

$$
e(t)=y(t)-y_{d}
$$

where:

$$
\begin{aligned}
& e(t)=\text { the error in the system. } \\
& y_{d}=\text { the reference and } y(t) \text { is the measured variable. }
\end{aligned}
$$

From the surface represented by Equation 13, the parameters $K_{p}$ and $K_{i}$ are selected which are constants defined in the system.

$$
z(t)=K_{p} e(t)+K_{i} \int_{0}^{t} e(\tau) d \tau
$$

In this way, Equation 14 defines the control signal of the system, where its purpose is to make the sliding surface $z(t) \rightarrow 0$.

$$
u(t)=\Gamma_{0} \operatorname{sig}[z(t)]
$$


Equation 15 is obtained from Equation 13.

$$
K_{p} e(t)+K_{i} \int_{0}^{t} e(\tau) d \tau=0
$$

Therefore, the solution is interpreted by Equation 16.

$$
K_{p} \dot{e}(t)+K_{i} e(t)=0
$$

Solving $\dot{e}(t)$ from Equation 15, Equation 17 is obtained.

$$
\dot{e}(t)=-\frac{K_{i}}{K_{p}} e(t)
$$

Equation 17 represents the objective of the controller to achieve that $e(t) \rightarrow 0$.

$$
\begin{gathered}
e(t)=e\left(t_{0}\right) e^{-\frac{K_{i}}{K_{p}} *\left(t-t_{0}\right)} \\
z(t)=K_{p} e(t)+K_{i} \int_{0}^{t} e(\tau) d \tau
\end{gathered}
$$

Equation 19 is used where $K_{p} K_{i}$ are constants defined in the objective sliding surface. The values of these constants are assumed with $K_{p}=100$ and $K_{i}=0.01$. The chosen values are intended to make the system respond in a more agile way to minimise the error as quickly as possible.

\section{$5 \quad$ Analysis of results}

Figure 11 shows the response signals of the PI controller with criteria and without criterion. From Figure 11 it can be seen that the criterion that has a better response in the system is the ICE criterion, because it has a better response time and establishment compared to the other criteria. Figure 12 shows the output signals of the different controllers implemented. The reference for controller responses is the ideal $\mathrm{pH}$ value for water (seven).

The control signals can be seen in Figure 13. It is observed that the control signal applied to the peristaltic pump ranges from zero to five volts. Table 2 presents a comparison of the control signals and closed-loop time response signals of the different types of controllers applied to the prototype.
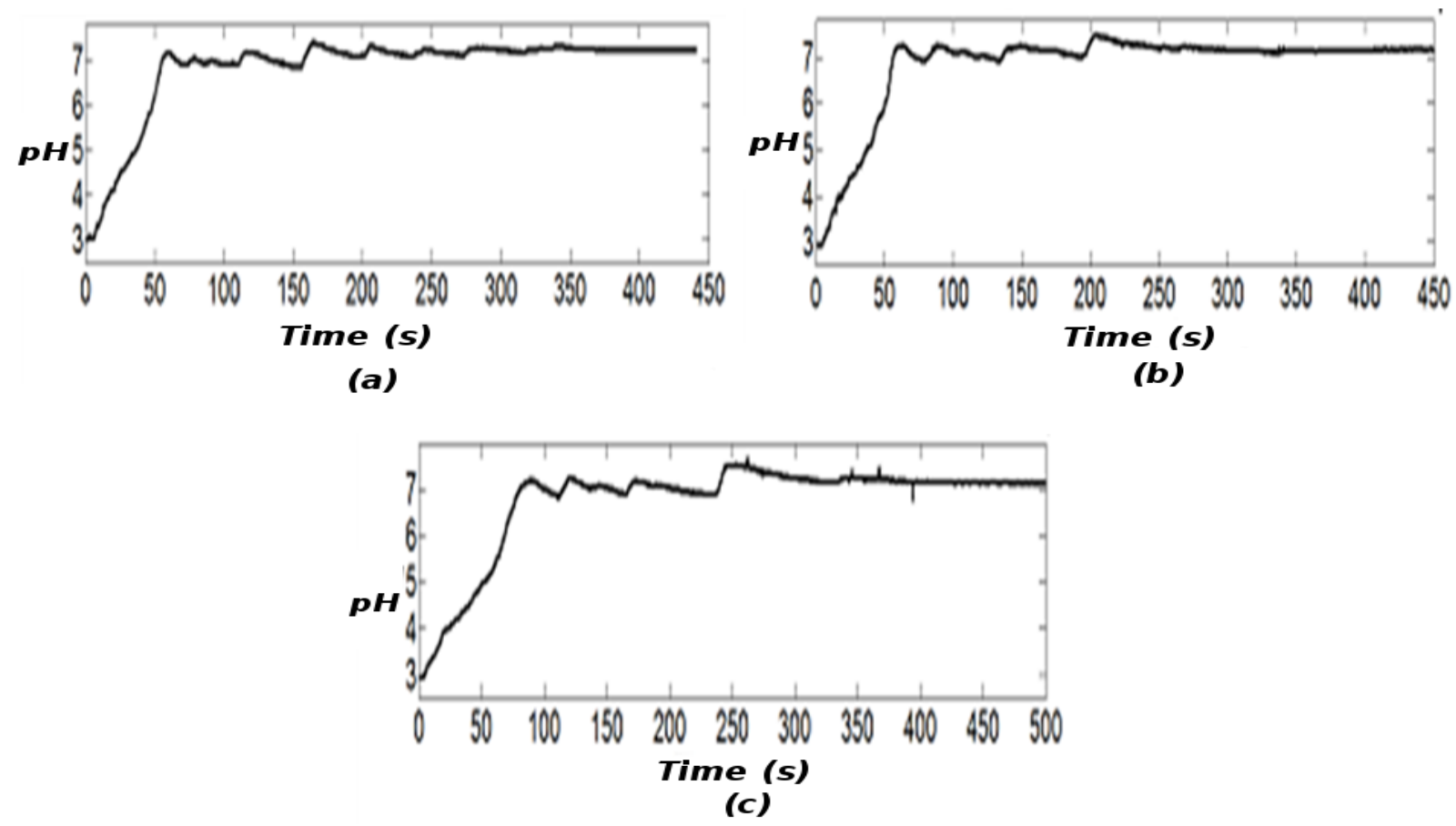

Figure 11 PI controller response; (a) Single PI; (b) ICE PI; (c) ITAE PI 


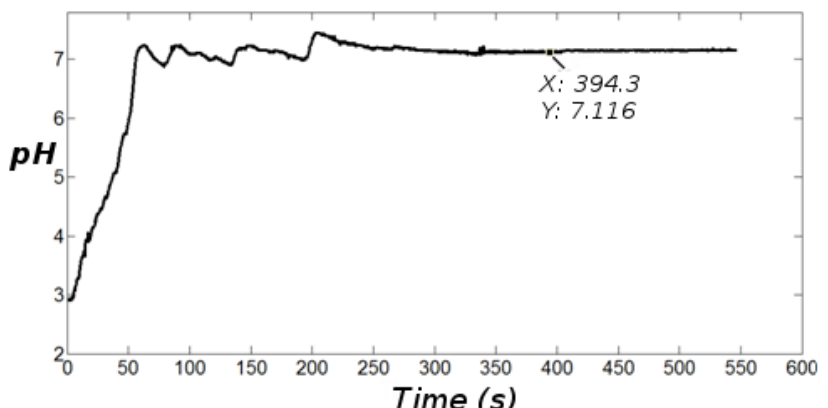

(a)

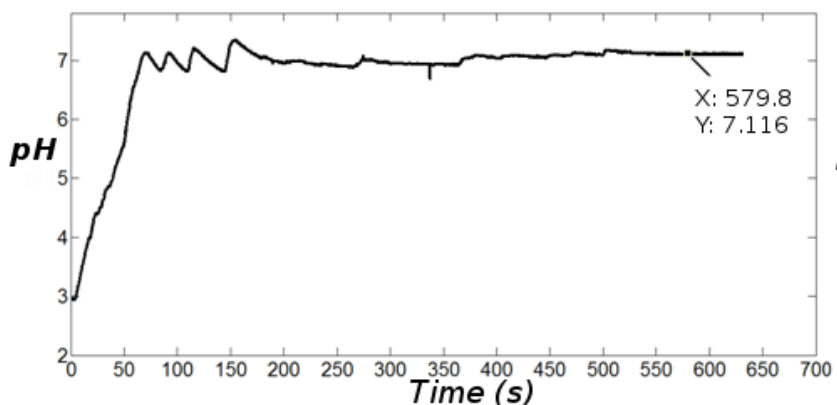

(c)

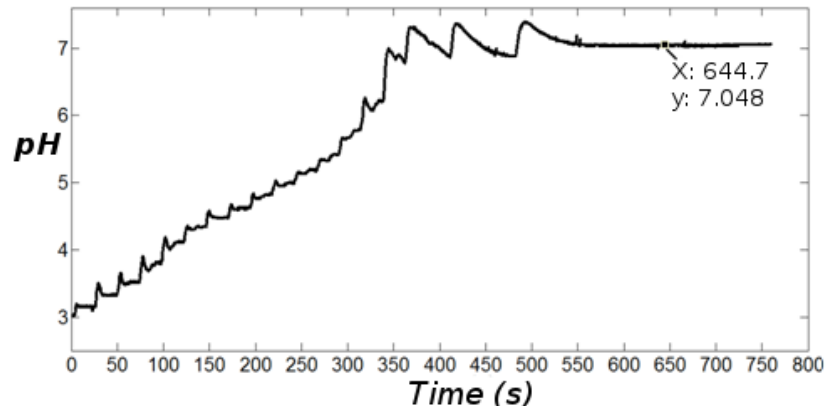

(b)

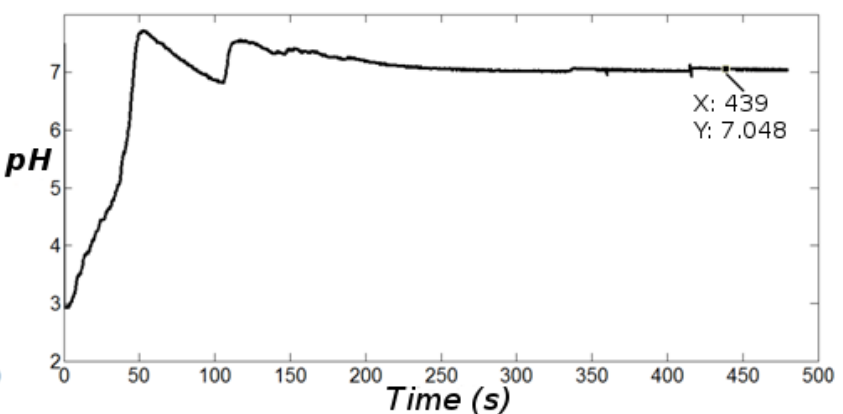

(d)

Figure 12 Comparison of the response of the implemented controllers; (a) PI; (b) Algebraic; (c) Fuzzy; (d) Sliding

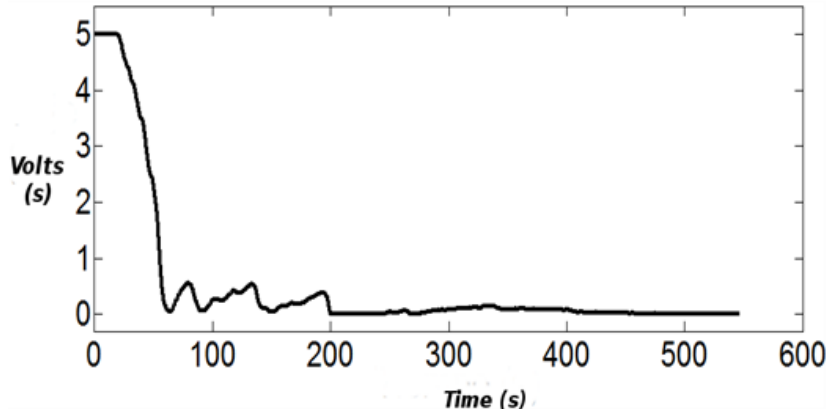

(a)

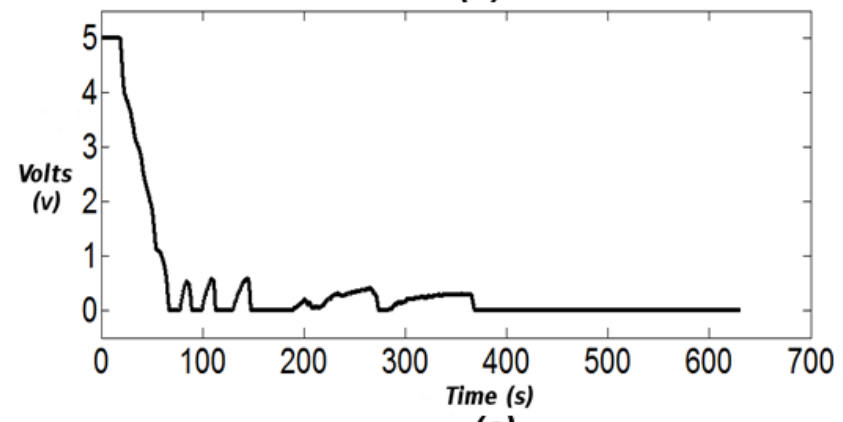

(c)

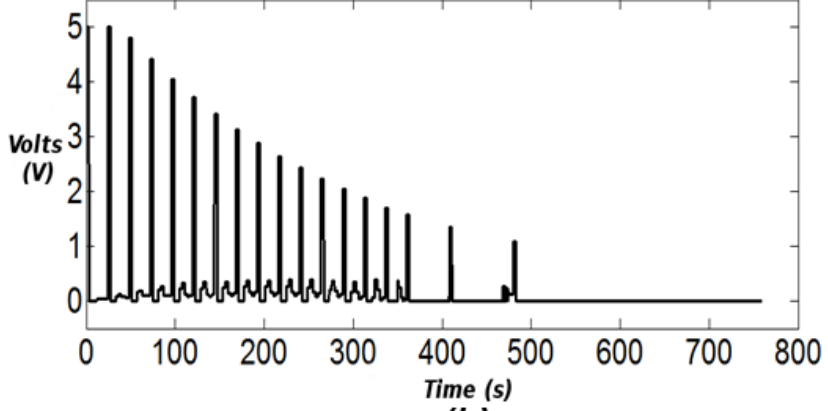

(b)

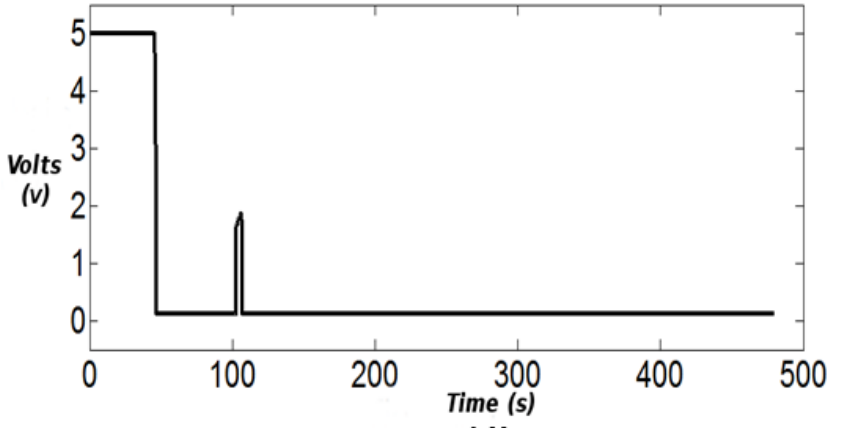

(d)

Figure 13 Control signal; (a) ICE PI; (b) Algebraic; (c) Fuzzy logic; (d) Sliding model 
Table 2 Comparison of controller's performance with respect to control signal size and time response

\begin{tabular}{|c|c|c|}
\hline \multicolumn{3}{|c|}{ Comparison of controller's performance } \\
\hline Controller & Control signal size & System response \\
\hline $\mathrm{PI}$ & $\begin{array}{l}\text { The system requires a slight } \\
\text { control signal, since it is } \\
\text { decreasing from } 5 \text { to } 0 \mathrm{~V} \text { in } 66 \mathrm{sec} \text {. } \\
\text { It has a response time of } 14.2 \mathrm{sec} \text {. }\end{array}$ & $\begin{array}{l}\text { The system response has an establishment } \\
\text { time, which occurs between } 300 \text { and } \\
400 \text { sec, a maximum overshoot of } 6.54 \% \text { and } \\
\text { an error of } 1.66 \% \text { with respect to the } \\
\text { reference value. }\end{array}$ \\
\hline $\begin{array}{l}\text { Algebraic } \\
\text { controller }\end{array}$ & $\begin{array}{l}\text { The control signal is quite } \\
\text { demanding because it has abrupt } \\
\text { changes of values between } 0 \text { and } \\
5 \mathrm{~V} \text {, with a time interval of } 24 \mathrm{sec} \text {. } \\
\text { It has a response time of } 1.7 \mathrm{sec} \text {. }\end{array}$ & $\begin{array}{l}\text { The system response has a set time between } \\
550 \text { and } 650 \text { sec, a maximum overlap of } \\
5.57 \% \text { and a rather low error }(0.69 \%) \text { with } \\
\text { respect to the reference value }\end{array}$ \\
\hline $\begin{array}{l}\text { Fuzzy logic } \\
\text { controller }\end{array}$ & $\begin{array}{l}\text { The required control signal is } \\
\text { slight, with a reduction of } 5 \mathrm{~V} \text { at } \\
0 \mathrm{~V} \text { in a time of } 67.2 \mathrm{sec} \text {. The } \\
\text { response time is } 6.9 \mathrm{sec} \text {. }\end{array}$ & $\begin{array}{l}\text { The system response has a settling time } \\
\text { between } 500 \text { and } 600 \mathrm{sec} \text {, a peak of } 4.84 \% \\
\text { and an error of } 1.66 \% \text { with respect to the } \\
\text { reference value. }\end{array}$ \\
\hline $\begin{array}{l}\text { Sliding mode } \\
\text { controller }\end{array}$ & $\begin{array}{l}\text { The control signal is required on } \\
\text { average because it has a maximum } \\
\text { voltage value of } 5 \mathrm{~V} \text { for } 45.7 \mathrm{sec} \text {. } \\
\text { It has a response time of } 3 \mathrm{sec} \text {. }\end{array}$ & $\begin{array}{l}\text { The system response has a set time between } \\
250 \text { and } 350 \mathrm{sec} \text {, has a rather high maximum } \\
\text { peak of } 10.21 \% \text {, although a rather low error } \\
(0.69 \%) \text { with respect to the reference value. }\end{array}$ \\
\hline
\end{tabular}

\section{Conclusions}

The design of the prototype is simple and easy to assemble, which makes it a practical plant for the application of control techniques.

The system is unstable because large variations in $\mathrm{pH}$ are produced in response to small variations in the volume of $\mathrm{NaOH}$ that is added to adjust the $\mathrm{pH}$ to seven. This instability prevents the controllers from reaching an error equal to zero and causes oscillations around the $\mathrm{pH}$ value.

The applications of the different control strategies present a good response both in rise time and stability time. Moreover, the error is not great even though the reference is in an unstable zone.

The three criteria for the PI controller stabilise the pH by seven. However, the error squared integral criterion does not present the overshoots generated by the controller without criterion and its response time is smaller than that obtained with the criterion of the integral of time-weighted absolute error.

The algebraic controller response time is higher than the other controllers implemented and its error is the lowest despite the difficulty of adjusting $\mathrm{pH} 7$ as a reference.

Comparing the controllers from the stability time and the error with respect to the $\mathrm{pH}$ setting of seven, the sliding mode control strategy has the lowest error and oscillations around the reference point. 


\section{References}

Åström, KJ \& Hägglund, T 2006, Advanced PID Control, ISA-The Instrumentation, Systems, and Automation Society, Research Triangle Park.

Åström, KJ \& Wittenmark, B 2011, Computer-Controlled Systems: Theory and Design, 3rd edn, Dover Publications, Mineola.

Banzi, M 2011, Getting Started with Arduino, O'Reilly Media, Sebastopol.

Barettino, D \& Pérez, JL 2005, Acidificación de Suelos y Aguas: Problemas y Soluciones, Instituto Geológico y Minero de España, Madrid.

Bequette, BW 1998, Process Dynamics: Modeling, Analysis, and Simulation, Prentice Hall, Upper Saddle River.

Betancourt, DP \& Ramírez, JL 2007, 'Por medio de la cual se señalan características, instrumentos básicos y frecuencias del sistema de control y vigilancia para la calidad del agua para consumo humano', Resolución Numero 2115, Ministerio de la Protección Social, Ministerio de Ambiente, Vivienda y Desarrollo Territorial, Bogota.

Bojadziev, G \& Bojadziev, M 1996, Fuzzy Sets, Fuzzy Logic, Applications, World Scientific Publishing Co., Inc. River Edge.

Distefano III, J, Stuberud, A \& William, I 1992, Retroalimentación y Sistemas de Control, McGraw-Hill, Contadero.

Evangelista, CA 2012, Control de Sistemas no Lineales por Modos Deslizantes de Segundo Orden, PhD thesis, Universidad Nacional De La Plata, Buenos Aires.

Garner, R, Naidu, T, Saavedra, C, Matamoros, P \& Lacroix, E 2012, Water Management in Mining: A Selection of Case Studies, International Council on Mining \& Metals, London.

Goilav, N \& Loi, G 2016, Arduino: Aprender a desarrollar para crear objetos inteligentes, ENI, Rome.

Kang, J, Wang, M \& Xiao, Z 2009, 'Modeling and control of pH in pulp and paper wastewater treatment process', Journal of Water Resource and Protection, vol. 1, pp. 122-127.

Kemmer, FN, McCallion, J \& Company, NC 1989, Manual del agua: su naturaleza, tratamiento y aplicaciones, McGraw-Hill, Contadero.

Kiam Heong, A, Chong, G \& Yun, L 2005, 'PID control system analysis, design, and technology', IEEE Transactions on Control Systems Technology, vol. 13, no. 4, pp. 559-576.

Monguí-Galvis, AM, Puentes-Balaguera, EA \& Ortega, R 2015, 'Diagnóstico y plan de gestión de manejo ambiental mina didáctica del SENA Facultad - Área de ingeniería', Ecomatemático, vol. 3, no. 1, pp. 74-83.

Passino, KM \& Yurkovich, S 1998, Fuzzy Control, Addison-Wesley, Boston.

Pedrera, AC 2017, Arduino para Principiantes, 2nd edn, Createspace, Scotts Valley.

Rivero Ochoa, EE \& Chávez Cuadros, T 2010, Diseño de una planta piloto para el tratamiento de aguas ácidas de mina, mina "Las Peñitas", en la vereda de Reginaldo, minicipio de Monguí - Boyacá, Universidad Pedagógica y Tecnológica de Colombia, Sogamoso.

Russell, DL, Ruiz, JB \& López, JC 2012, Tratamiento de Aguas Residuales: Un Enfoque Práctico, Editorial Reverté S.A., Barcelona.

Salamanca, J 2009, Analisis y Control con Modelos Algebraico Diferenciales Lineales de la Estabilidad en Pequea Seal en Sistemas de Potencia Electrica, PhD thesis, Universidad del Valle, Cali.

Salamanca, J, Rodríguez, EA \& Rosas, RP 2010, 'Control por LMI-Modos deslizantes aplicado a una clase de sistemas no lineales', Proceedings of VIII Congreso Internacional sobre Innovación y Desarrollo Tecnológico, Institute of Electrical and Electronics Engineers, Piscataway.

Smith, CA \& Corripio, AB 2006, Principles and Practice of Automatic Process Control, John Wiley \& Sons, Hoboken.

The MathWorks, Inc. 2017, Simulink, version R2017a, The MathWorks, Inc., Natick https://www.mathworks.com/products/ simulink.html 
